\title{
Da zona rural à escola urbana: problematizando relações pedagógicas entre professoras e crianças
}

\author{
From the rural area to the urban school: problematizing pedagogical \\ relations between teachers and children
}

\section{De la zona rural a la escuela urbana: problematizando relaciones pedagógicas entre profesoras y niños}

\section{Luana Zanotto'}

Universidade Federal de São Carlos, Programa de Pós-Graduação em Educação, Centro de Pesquisa da Criança e de Formação de Educadores da Infância, Estudante do Doutorado

\section{Fernando Donizete Alves ${ }^{2}$}

Universidade Federal de São Carlos, Departamento de Educação Física e Motricidade Humana, Programa de Pós-Graduação em Educação, Centro de Pesquisa da Criança e de Formação de Educadores da Infância, Docente

\section{Aline Sommerhalder ${ }^{3}$}

Universidade Federal de São Carlos, Departamento de Teorias e Práticas Pedagógicas, do Programa de Pós-Graduação em Educação, Centro de Pesquisa da Criança e de Formação de Educadores da Infância, Docente

Resumo: 0 presente estudo focaliza as práticas pedagógicas de duas professoras - pedagoga e educadora física - na relação com um grupo de crianças residente em zona rural, inserido em uma escola municipal situada em perímetro urbano de uma cidade do interior do Estado de São Paulo. Nessa direção, objetivou compreender como ocorre a relação entre as professoras e as crianças no cotidiano das práticas pedagógicas. Os participantes foram 11 crianças estudantes do terceiro ano do ensino fundamental e duas professoras responsáveis pela turma (uma pedagoga e uma educadora física). Com base na abordagem qualitativa de pesquisa foi realizada observação participante em dois espaços escolares em que crianças e professoras convivem: na sala de aula e na quadra poliesportiva. Para sistematização das informações foram realizados registros em diário de campo. Todo o material coletado foi interpretado e categorizado via análise de conteúdo. Os resultados revelam relações positivas entre professoras e crianças. Por outro lado, revelam as dificuldades enfrentadas nas práticas pedagógicas com a população rural inserida na escola urbana, sobretudo no que concerne às diferenciações dos contextos de vida que perpassam o espaço rural onde vivem as crianças. Assim, há uma implicação nos

Mestre em Educação pela Universidade Federal de São Carlos; Licenciada em Educação Fisica pela Universidade Federal de São Carlos; http://orcid.org/0000-0002-0689-9112; http://lattes.cnpq.br/9718778267626503.

2 Doutor em Educação Escolar pela Universidade Estadual Paulista; Mestre em Ciências da Motricidade pela Universidade Estadual Paulista; http://orcid.org/0000-0002-9354-7851; http://lattes.cnpq.br/3812723309905378.

3 Doutora em Educação Escolar pela Universidade Estadual Paulista; Mestre em Ciências da Motricidade pela Universidade Estadual Paulista; http://orcid.org/0000-0002-6024-0853; http://lattes.cnpq.br/4775432120371947. 
saberes experienciais construidos nos intramuros da escola, os quais remetem à reflexão sobre como se realiza a formação inicial e continuada de professores que atuam com crianças moradoras da zona rural. Palavras-chave: Práticas pedagógicas. Crianças de zona rural. Escola urbana.

Abstract: This study focuses on the pedagogical practices of two teachers - pedagogue and physical educator - in relation with a group of children who live in the countryside, inserted in a municipal school located in the urban area of a city in the state of São Paulo. In this direction, the study aimed to understand how is the interaction between teachers and children in the context of pedagogical practices. The participants were eleven children students of the third year of elementary school and two teachers responsible for the class (an pedagogue and a physical educator). Based on qualitative research was conducted participant observation in two school spaces where children and teachers live together: in the classroom and on the sports field. For systematization of information were done records out in a field diary. All the collected material was interpreted and categorized through content analysis. The results reveal positive relationships between teachers and children. On the other hand, it shows the difficulties faced in pedagogical practices with the rural population inserted in the urban school, especially as concern the differentiations of life contexts that pervade the countryside where children live. Thus, there is an implication in the experiential knowledge built in school intramural, which lead to the reflection on how is the initial and ongoing training of teachers who work with children living in the countryside.

Keywords: Pedagogical Practices. Children of the countryside. Urban school.

Resumen: El presente estudio se centra en las prácticas pedagógicas de dos profesoras - pedagoga y educadora física - en la relación con un grupo de niños residente en zona rural, insertado en una escuela municipal situada en perímetro urbano de una ciudad del interior del Estado de São Paulo. En esa dirección, objetivó comprender cómo se da la relación entre las profesoras y los niños en el cotidiano de las prácticas pedagógicas. Los participantes fueron once niños estudiantes del tercer año de la enseñanza primaria y dos profesoras responsables de la clase (una pedagogía y una educadora físical. Con base en el abordaje cualitativo de investigación se realizó observación participante en dos espacios escolares en que niños y profesoras conviven: en el aula y en la cancha polideportiva. Para sistematización de las informaciones se realizaron registros en diario de campo. Todo el material recolectado fue interpretado y categorizado a través del análisis de contenido. Los resultados revelan relaciones positivas entre profesoras y niños. Por otro lado, revelan las dificultades enfrentadas en las prácticas pedagógicas con la población rural insertada en la escuela urbana, sobre todo en lo que se refiere a las diferenciaciones de los contextos de vida que atravesan el espacio rural donde viven los niños. Así, hay una implicación en los saberes experienciales construidos en los intramuros de la escuela, los cuales remiten a la reflexión sobre cómo se da la formación inicial y continuada de profesores que actúan con niños moradores de la zona rural.

Palabras clave: Prácticas pedagógicas. Niños de zonas rurales. Escuela urbana.

Recebido em 19 de julho de 2018 Aceito em 10 de outubro de 2018 Publicado em 25 de abril de 2019 


\section{INTRODUÇÃO}

0 presente artigo discute as práticas pedagógicas de duas professoras, uma pedagoga e educadora física, na relação com um grupo de crianças residente em zona rural, em uma escola municipal situada em perímetro urbano de uma cidade do interior do Estado de São Paulo, Brasil. Teve como objetivo compreender como ocorre a relação entre as professoras e as crianças de zona rural no cotidiano das práticas pedagógicas.

A discussão acadêmica e científica acerca da temática da educação do, no e para o campo não é recente na área das Ciências Humanas, especialmente na Educação (SANTOS, 1988; DAMASCENO; BESERRA, 2004; STROPASOLAS, 2012). 0 anseio de pesquisadores em compreender as relações estabelecidas entre as populações da cidade e as populações do campo soma-se às inquietudes e à carência de reconhecimento e valorização das condições sociais, políticas e econômicas dos sujeitos pertencentes às zonas rurais dos municípios.

0 ponto que desperta o nosso interesse na investigação dessa temática corresponde ao fato de a construção da concepção do cenário rural no imaginário da sociedade brasileira estar frequentemente associada à ideia de atraso cultural e tecnológico e/ou como espaço de não desenvolvimento e sem acesso às infraestruturas e serviços básicos. Segundo Biazzo (2008), a reprodução da hierarquia "urbano x rural" se realiza a partir da construção estigmatizante de que morar em zonas rurais representa inferioridade social e cultural, processo manifesto, também, na percepção dos distintos estilos de vida.

Para uma melhor compreensão desses conceitos, a seguir aclaramos algumas explanaç̃̃es conceituais - históricas e culturais - sobre as terminologias "rural" e "urbano", bem como elucidamos, à luz das teorias, alguns conceitos mistificados que perpassam 0 conceito de zona rural.

Veiga (2004) propõe uma maneira adequada para classificar as expressões "zona rural" e "zona urbana". Consoante o autor, os critérios de definição para ambos os termos englobam todas as manifestações e características que compõem os espaços, em particular, pelos seres humanos que os ocupam. Assim, a conceitualização do termo "zona rural" pauta-se nos elementos evidenciados nas características geográficas, históricas, politicas, econômicas e sociais. Tais elementos também foram considerados nas relações das crianças em contexto escolar.

Assim, neste trabalho optamos por adotar a expressão "zona rural" para nos referir à Educação do Campo, povos do campo, entre outras expressões similares como reflexo dos modos de vidas humanas no campo. Em outras palavras, compreendemos o termo zona rural como um universo que não é isolado, tampouco inferiorizado, mas que 
carrega especificidades sociais, construídas através da história. Parafraseando Martins (1981, p. 23), "acreditando no rural como formação sócio-histórica concreta."

Santos (1988), por sua vez, adota as categorias "ruralidade" e "urbanidade" como referência ao processo social de um determinado espaço. Ambos os autores conferem ao mundo rural não apenas limítrofes em espaços físicos, mas também aos modos de vida e às manifestações do rural desvencilhadas em diversas circunstâncias. Em outras palavras, ruralidades e urbanidades são tratadas como conteúdos de construções culturais, e campo e cidade são, portanto, a materialidade/o espaço físico. Portanto, acreditamos que zona rural e zona urbana são termos definidos a partir das concepções de conteúdos e significados das práticas sociais realizadas em ambos os espaços; concepções estas construídas por um sentido próprio e mediante o avanço de estudos desenvolvidos no campo das Ciências Humanas.

Ainda, embora conscientes do amplo debate existente entre os pesquisadores que se debruçam em estudos sobre a educação do, no e para o campo e, assim, optam pela terminologia "campo" em vez de "rural" (inclusive adotada nas Diretrizes Operacionais para a Educação Básica nas Escolas do Campo (BRASIL, 2002)), defendemos nossa posição pela adoção do termo "zona rural", pois, para além de referir-se aos conceitos de ruralidades, foi desse termo que as crianças e as educadoras (sujeitos desta pesquisa) se apropriaram e se utilizaram no cotidiano escolar, ou seja, nomeavam-se e/ou distinguiam como sendo de "zona rural".

Avançando na discussão, temos que os sujeitos que vivenciam a sua infância e juventude nas nomeadas zonas rurais são afetados por uma caracterização pejorativa do seu cotidiano, isto é, a vinculação desses territórios com o atraso e isolamento social e o julgamento da identidade social como "colonos", "roceiros" e "peões". Sem dúvidas tais representações necessitam ser problematizadas, desnaturalizadas e, obviamente, questionadas por todos aqueles que interagem, ou não, com o público de zona rural.

Para Leite (2002), a escola enquanto espaço destinado ao convívio social também comunga de concepções e ideários mistificados acerca da população infantil rural, pois em âmbito escolar urbano propriamente, as relações geradas entre as crianças e as professoras podem ser expressas por certo distanciamento entre a visão de mundo urbana e a visão de mundo rural. Tal distinção de contextos de vida, na relação entre criança-criança, pode acarretar posturas de preconceitos e discriminações, desencadeando sentimentos de inferioridade e marginalização. Do mesmo modo, na relação criança-professora, por vezes, originam-se processos de ensino e aprendizagem descontextualizados e desconexos com os anseios e necessidades das crianças de zona rural.

Com isso, acreditamos que a instituição escolar de modo integral possui importância ímpar no processo de problematização desses conceitos e de acolhimento das diferentes 
culturas - fenômeno que atribui à escola um lugar, tempo e espaço para construção e reconstrução cultural.

\section{REUISÃO BIBLIOGRÁFICA}

As informações divulgadas pelo MEC/INEP (INSTITUTO NACIONAL DE ESTUDOS E PESQUISAS EDUCACIONAIS ANISIO TEIXEIRA, 2010) demonstram que as crianças nascidas na zona rural possuem menores chances de frequentar a escola em comparação com as crianças nascidas na cidade. Conforme o senso demográfico do Instituto Brasileiro de Geografia e Estatística (IBGE) (2010), a taxa de analfabetismo da população de 15 anos ou mais na zona rural é de $29,8 \%$, e na zona urbana esse número apresenta $10,3 \%$. 0 número referente aos anos de estudo das populações nessa mesma faixa etária é de 3,4 anos na zona rural, o que representa menos que a metade da zona urbana, que é de sete anos (INSTITUTO NACIONAL DE ESTUDOS E PESQUISAS EDUCACIONAIS ANISIO TEIXEIRA, 2010).

Segundo Damasceno e Beserra (2004), até meados da década de 1980, praticamente todas as grandes fazendas situadas em regiões do Estado de São Paulo possuíam escolas primárias destinadas ao atendimento das necessidades consideradas básicas de escolarização dos filhos dos trabalhadores rurais. Contudo, atualmente, não são todas as regiões rurais dos municípios que atendem à demanda no próprio campo.

\footnotetext{
Desse modo, a escolinha isolada e as suas classes multisseriadas, que já foram o retrato mais comum do ensino no meio rural brasileiro, vêm se tornando cada vez mais raras em muitas regiões do pais. Observase, em contrapartida, a aglutinação de escolas e, consequentemente, a concentração de alunos de uma dada área numa mesma escola de maior porte, seguindo o modelo do grupo escolar urbano, tornando-se, assim, possivel levar para o campo o ensino fundamental completo (DAMASCENO; BESERRA, 2004, p. 82).
}

Diante de tais circunstâncias, comumente, a escola fica localizada fora da comunidade de origem, exigindo que as famílias se organizem para garantir a inserção das crianças nas escolas urbanas. As autoras citadas pontuam que a modificação desse cenário requer grandes investimentos em dois setores: "a) a construção de escolas maiores [...] para comportar os estudantes da microrregião onde a escola se situa e b) o do transporte escolar, serviços que os municípios implantaram para cumprir a lei que os obrigam manter as crianças na escola." (DAMASCENO; BESERRA, 2004, p. 82-83). 
Para Stropasolas (2012), o não acesso à escola e os altos índices de evasão encontrados em territórios rurais podem ser justificados (dentre outras limitações e dificuldades de acesso às dependências escolares) pelo fato de os projetos pedagógicos desenvolvidos na área urbana dos municípios em que frequentam as crianças de zonas rurais nem sempre reconhecerem as especificidades constitutivas da diversidade do mundo/ vida rural, desprezando tradições, valores e identidades em favor de um mundo único, civilizado e educado ao qual todos devem ser submetidos.

Assim, a instituição escola permanece como um palco conflitual de projetos político-pedagógicos que tanto podem orientar para o reconhecimento e valorização dessas identidades infantis, por meio do efetivo exercício da inclusão social e da promoção de iniciativas que buscam a ampliação dos direitos de cidadania, quanto se pautar em modelos e lógicas de intervenção que produzem opressão e dominação dos saberes, atitudes e opiniões das crianças.

No tocante à educação de qualidade social, sabemos que esta é conquistada de maneira singular e coletiva, supondo apreender a articulação entre o local e o universal em diferentes tempos, espaços e grupos sociais. Nessa lógica,

\footnotetext{
[... a qualidade da educação para todos exige compromisso e responsabilidade de todos os envolvidos no processo político, que o Projeto de Nação traçou, por meio da Constituição Federal e da LDB, cujos princípios e finalidades educacionais são desafiadores: em síntese, assegurando o direto inalienável de cada brasileiro conquistar uma formação sustentada na continuidade de estudos, ou seja, como temporalização de aprendizagens que complexifiquem a experiência de comungar sentidos que dão significado à convivência. (BRASIL, 2003, p. 14).
}

À medida que diversos aspectos que marcam a vida social do público rural forem reconhecidos e valorizados e estiverem presentes nas preocupações nos currículos das instituições, poder-se-á viabilizar um processo de interpretação e compreensão das condições sociais, econômicas e culturais experimentadas por essa população. Assim, também se atenderá ao previsto nas Diretrizes Operacionais para uma Educação do Campo (BRASIL, 2002) no que confere à regulamentação de estratégias específicas de atendimento escolar do campo (e as escolas que atendem à demanda do campo), salvaguardando espaços pedagógicos e tempos distintos de aprendizagem.

Acreditamos que as ações educativas compartilhadas entre a gestão escolar e as crianças podem contribuir para a reconstrução e o aprimoramento das práticas de aprendizagem, de formação cidadã, de socialização e de inclusão, já que tais ações cotidianas 
da escola - salvo se em coerência com as especificidades da cultura rural - contribuem para a construção de identidades positivas, para além de garantir e ampliar oportunidades igualitárias.

Quanto mais evidente for a reconstrução de práticas de respeito às diferenças e de aproximação das realidades culturais das crianças, mais se estará potencializando as virtualidades educativas dos saberes próprios, valorizando e aguçando o multiculturalismo tão presente e característico do ambiente escolar. Do mesmo modo, quanto mais as organizações escolares atenderem a um determinando grupo de sujeitos, sua linguagem, seus valores e sua cultura, menos possibilidade haverá para que se reconheçam outras linguagens e outros saberes.

Ao organizarem diretrizes para a proposição de uma escola cidadã, solidária e com qualidade social, bem como um Ensino Fundamental como direito público e universalizado, os órgãos normativos e executivos das redes e sistemas de ensino assumem o compromisso com a implementação e execução de políticas indutoras de transformações significativas à estrutura de todas as etapas de ensino, na reorganização dos tempos e dos espaços, nas formas de ensinar, aprender, avaliar, organizar e desenvolver o currículo, trabalhando com o conhecimento e respeitando as particularidades das crianças.

Ao vivenciarem o espaço escolar, as crianças produzem posturas e valores inerentes a sua condição e tornam-se produtoras de uma cultura própria, que acresce à cultura escolar. Em diálogo com Freire (1993, p. 16) entendemos que elas agem como parte ativa e constituinte da cultura que se cria na escola, pois "não devemos chamar o povo à escola para receber instruções, postulados, receitas [...], mas para participar coletivamente da construção de um saber, que leve em conta a suas necessidades, possibilitando-lhe transformar-se em sujeito de sua própria história." Dessa forma, o educador politicamente engajado deve considerar as especificidades das crianças, pois elas participam do processo educativo, no tocante às suas formas de aprender, às trajetórias de vida, ao gênero, à classe, à idade, à cultura, às crenças e valores. Assim, Bosi (1992, p. 309) atenta para o fato de que "o reconhecimento do plural é essencial."

Apoiados em Bezerra Neto (2010), vemos que a defesa de uma escola específica para o sujeito do campo é inadequada, pois assim se estará fragmentando os conhecimentos destinados aos distintos segmentos sociais. Para o autor, a escola deve ser única, regidas por políticas que tenham caráter universalista, de modo a garantir o acesso de todos aos conhecimentos historicamente sistematizados. É preciso entender, no entanto, que embora a escola tenha sido negada a grande parcela da sociedade, ela deve fazer parte da vida de todas as pessoas, em sua função de ser "agência socializadora de saber ou democratizadora dos conhecimentos socialmente produzidos, necessários à participação e à cidadania." (ARROYO, 1982, p. 6). 
Nesse sentido, é importante que os educadores saibam o que se passa no mundo das crianças com que trabalham, acerca do universo das suas vivências cotidianas, dos seus sonhos, das linguagens, das angústias e do que sabem e como sabem, independentemente da cultura incutida pela escola. Tal postura de reconhecimento pelo outro perpassa pelo compromisso ético e social para com a cultura, na busca por diálogo, equidade, respeito à vida, dignidade das pessoas e valorização dos seus saberes. Aqui se coloca uma questão importante: a convivência nos intramuros escolares entre crianças e entre elas e os adultos. Oliveira (2009, p. 315) afirma que

[..] conviver é mergulhar nos processos vivos da educação, saúde, sobrevivência e luta, os quais o(a) pesquisador(a), ou o(a) profissional, se dispõe a compreender. Conviver é conhecer a vida humana sempre em movimento: ora suave, ora abrupto; ora lento, ora vertiginoso; ora leve, ora sufocante; ora harmonioso, ora ensurdecedor.

Por meio da convivência, os saberes, conceitos e ideias são construídos e compartilhados. Nesse movimento ocorrem processos educativos e a produção de cultura como "permanente recriação do mundo, da existência [...]" (FIORI, 1991, p. 89).

A convivência, seja harmoniosa, dialógica ou marcada por conflito e tensões, é construída continuamente. Dessa forma, os espaços escolares surgem como meios facilitadores de discussões sobre como são organizados os modos para conviver com determinado grupo, caracterizando e dialogando sobre a participação e a compreensão que as crianças constroem sobre sua inserção nesse ambiente.

De maneira análoga, ancoramo-nos no documento de criação do Fórum Nacional de Educação do Campo (Fonec) para compreender e afirmar que cabem às escolas, antes de tudo, zelar pelo cumprimento do direito humano inalienável e indivisível à educação de qualidade social a todos os que vivem no e do campo, salvaguardadas, sempre, a diversidade cultural e as especificidades sociais e ambientais da vida e do trabalhador dos povos do campo.

A escola deve compor-se por um espaço acolhedor, pronto para ouvir com atenção quem dele participa, ou seja, crianças, professores, coordenadores, diretores, e também outros agentes que participam da rotina escolar, como os cozinheiros, os zeladores, os vigias, etc. Se não compreendido dessa forma, a escola passa a ser um espaço de pertencimento a ninguém, como não pertence às crianças, "[...] é como se os educandos estivem apenas neles, mas não com eles." (FREIRE, 1993, p. 73).

Olhamos para as crianças de zona rural como parte de grupos sociais que possuem particularidades na organização e funcionamento das atividades econômicas e das singularidades culturais e históricas e na vida social, assim como as demais condições 
infantis. Por isso, condiz à escola vir ao encontro com práticas que estimulem a sociabilidade, a ajuda mútua e o convívio coletivo entre as crianças e entre elas e outras gerações. Nesse sentido, um dos papéis principais da equipe escolar é pensar o currículo para que os distintos espaços sejam dialogáveis com as perspectivas e os anseios das crianças. Trata-se de forjar uma escola onde as crianças tenham condições de criar, de arriscar, de perguntar, de crescer, de aprender e de ensinar.

A condição de reconhecimento e valoração de saberes das infâncias pode ser observada em simples afazeres cotidianos, não importa se com deslizes e com incoerências, mas desde que os sujeitos estejam dispostos a reconhecer uns aos outros, por meio da humildade, da amorosidade, da tolerância, da competência, da capacidade e disponibilidade para dizer e ouvir, da eticidade e da justiça, balizados em aspectos que contribuam para a criação de uma escola coerente e democrática.

Nesse movimento, repensar o contexto escolar e colaborar para a formação de uma escola que auxilie na "construção da própria vida (SILVA, 2003, p. 181) [que se desenvolva] nas relações entre gerações, gêneros, grupos raciais e sociais, com a intenção de transmitir visão de mundo, repassar conhecimentos, comunicar experiências" - é imprescindível que se escute o interesse das crianças no que tange às peculiaridades dos contextos em que vivem.

Por esse viés, ouvir as vozes das crianças e reconhecer o seu direito de uso das palavras se coloca como imperativo categórico do educar-se, o que assume implicações diretas com o plano de ensino e com os modos de planejamento da escola nos afazeres cotidianos.

\section{METODOLOGIA}

A pesquisa foi realizada em uma Escola Municipal de Ensino Fundamental (EMEF) de uma cidade do interior de São Paulo, Brasil. Trata-se da única instituição escolar da cidade destinada a ofertar vagas para estudantes entre seis e dez anos de idade - crianças no Ensino Fundamental do primeiro ciclo - advindas da zona rural da região.

A pesquisa contou com a participação de 1 crianças entre oito e nove anos de idade, sendo sete meninas e quatro meninos, estudantes da única turma do terceiro ano da escola. A escolha dessa turma ocorreu em virtude de as crianças possuírem um maior contato com a instituição escolar, neste caso, dois anos ou mais, contribuindo, assim, para ampliação das experiências em âmbito escolar. Somaram-se ao grupo de crianças participantes as duas professoras da turma: a pedagoga, diariamente com as crianças e que trabalha na escola desde 2000, e a educadora física, recém-chegada à escola e responsável pelas duas horas-aulas semanais com a turma. 
0 estudo sustentou-se na abordagem qualitativa (ANDRÉ, 1994). Como procedimento metodológico realizou-se a observação participante, que oferece um maior contato com os participantes da pesquisa, igualmente favorecendo os estreitamentos de vínculos pautados em uma relação de confiança que permite chegar mais próximo da realidade social inserida (LUDKE; ANDRÉ, 2012).

Assim, buscando estar presente nas vivências apreendidas pelas crianças, sobretudo nas práticas pedagógicas desencadeadas pelas professoras, optou-se por realizar as inserções em dois espaços escolares, na sala de aula e durante as aulas de educação física, na quadra poliesportiva. As inserções no campo de pesquisa ocorreram com uma frequência de duas a três vezes por semana, em geral distribuidas entre as segundas, quartas e sextas-feiras no horário compreendido entre 7 e 10h, ao longo dos meses de setembro, outubro, novembro e meados de dezembro - até o encerramento do ano letivo de 2014, totalizando 32 inserções.

Importante ressaltar que as professoras e os responsáveis pelas crianças assinaram o Termo de Consentimento Livre e Esclarecido (TCLE). As crianças, além do consentimento dos respectivos responsáveis, indicaram seu interesse em participar pelo Termo de Anuência Livre e Esclarecido (TALE). Os nomes verdadeiros foram alterados por nomes fictícios escolhidos por eles próprios, a fim de garantir sigilo da identidade e privacidade das crianças e professoras.

Para o registro das observações foram utilizadas notas de campo em diários de campo, na perspectiva considerada por Bogdan e Biklen (1994, p. 152): "notas de campo são relatos escritos daquilo que o investigador ouve, vê, experiencia e pensa no decurso da recolha refletindo sobre os dados de um estudo qualitativo." Os diários de campo foram feitos diariamente e de maneira detalhada, decorrente da rotina das crianças e das atividade pedagógicas desenvolvidas, de modo a ilustrar de forma próxima ao real os episódios vivenciados em cada inserção da unidade escolar.

Para a análise e discussão dos dados, todo o material produzido na fase de coleta foi agrupado, via densas leituras, e foram feitas análises por meio das bases teóricas da análise de conteúdo proposta por Bardin (2009). Nesse processo buscamos abstrair o sentido e o significado expressos nas mensagens, sejam elas orais, escritas, gestuais, silenciosas, figurativas ou documentais, visando compreender como as crianças significam os tempos e espaços escolares.

Depois de cumpridas todas as etapas descritas por esse método, especialmente a identificação das unidades de registro e de contexto contidas nos diários de campo, emergiram duas categorias temáticas articuladas, as quais se inseriram no objetivo geral da pesquisa, 
nomeadas da seguinte maneira: (a) Relações crianças-professoras no cotidiano escolar: encontros e desencontros e (b) Aspectos educativo-pedagógicos nas práticas docentes.

\subsection{RELAÇÕES ENTRE CRIANÇAS E PROFESSORAS NO COTIDIANO ESCOLAR: ENCONTROS E DESENCONTROS}

Nesta categoria, apresentamos elementos de convivência entre as professoras e as crianças no dia a dia da escola, particularmente no contexto da sala de aula. As crianças demonstraram ter abertura para dialogar com ambas as professoras, sendo que suas vozes eram ouvidas e consideradas com respeito pelas docentes. Durante as inserções, foram observados episódios em que tanto as crianças quanto os adultos puderam falar sobre si mesmos e compartilhar curiosidades sobre o momento vivido ou sobre acontecimentos da vida particular. 0 excerto abaixo indica uma situação em que as crianças demonstram ter conhecimento sobre a vida particular da pedagoga:

\footnotetext{
A inspetora abre a porta da sala de aula e pergunta à professora: "Seu pai está bem? Ele melhorou?" Essa questão foi feita em voz alta, possibilitando com que as crianças ouvissem. Imediatamente, Letícia pergunta: "Ah, é verdade... Professora, seu pai já tá bonzinho?" Percebi que as crianças já sabiam que o pai da professora estava doente. Considerei interessante saber que as crianças têm conhecimento parcial sobre a vida pessoal da professora, já que, por caráter da própria docência, a professora tende a ter uma participação maior na vida das crianças do que o contrário. (Diário de campo XVI, 23-10-2014).
}

Os espaços de aproximação de vidas entre professor-estudante possibilitam que os vínculos entre eles sejam ainda mais estreitos, o que pode favorecer e fortalecer o processo de ensino e de aprendizagem. Segundo Sommerhalder e Alves (2012), a professora torna-se objeto de desejo da criança, por quem desenvolve grande empatia. É a pessoa da professora que está em primeiro plano. Esse processo desencadeia certa afinidade entre criança e professora, o que pode fazer com que a criança se apaixone pelo conteúdo pedagógico a partir do modo como a professora o apresenta, somado à construção de vínculos afetivos com ele.

Dessa forma, a análise da convivência com o grupo nos permitiu perceber o grande empenho e interesse da turma em apreender os conteúdos escolares, fato possivelmente justificado pelo contato estreito e de amorosidade pela pedagoga e que remete a indícios 
de que a aprendizagem se resulta possível a partir da presença do outro, neste caso, da professora como o outro humano na relação educativa.

Quanto às relações estabelecidas com a educadora física, a partir da convivência com o grupo captou-se que ela expressou grande preocupação em incentivar as práticas de atividades físicas (campo de conhecimento do componente curricular em questão), ao mesmo tempo em que assumiu posturas abertas para o diálogo e tentativas de criar vínculos estreitos com as crianças, já que se encontram apenas duas vezes por semana.

Interessante destacar que essa professora assiduamente participava de brincadeiras iniciadas e desenvolvidas pelas crianças em momentos de interação livre entre pares (CORSARO, 2011). Contudo, e ainda que possibilitasse a criação e organização de momentos lúdicos, a professora não avançava na discussão daquilo que era produzido pelo coletivo de crianças da zona rural. Como exemplo, pode-se observar a interação de um grupo de crianças em uma dessas brincadeiras.

\footnotetext{
Samuel, Violeta e Raul estão brincando de cerquinha, onde Violeta é o filhote do cachorro que acabou de dar cria. Samuel é quem vem dar comida para as galinhas e ficam ao lado da cerca dos filhotes. Raul, também como filhote, rola no chão da quadra demonstrando estar faminto e esperando o dono chegar com a comida. Em meio a brincadeira, chega a professora dizendo em tom alto de voz para que os três se levantem, justificando que o ficar ali - rolando - iria deixá-los sujos para voltar para a sala de aula [...] Pediu para eles brincarem em pé e não de animais [...] (Diário de campo IV, 09-09-2014).
}

Tal momento poderia ter sido contemplado para a aproximação da professora com essas crianças, questionando-as sobre a origem da história das cercas e do papel do animal em seus respectivos espaços, assim, podendo se aproximar um pouco mais do contexto extraescolar vivenciado por elas. Da mesma forma, compreender a brincadeira pode ser um meio importante para conhecer as demandas e interesses das crianças, o que pode possibilitar maior aproximação entre os anseios das crianças e o seu planejamento pedagógico. Isso significa partir do "saber de experiência feito" das crianças, termo que para Freire (1996, p. 53) se refere às experiências de vida trazidas pelos sujeitos, as quais devem ser consideradas em seus contextos históricos e traduzem a leitura de mundo dos sujeitos se tomadas como ponto de partida nas relações humanas e educativas.

Além disso, o interesse da educadora poderia contribuir para a melhoria do diálogo com as crianças, tornando o ambiente escolar mais acolhedor. De acordo com Freire (1993, p. 22), cabe à escola vislumbrar um espaço acolhedor e multiplicador de atitudes democráticas, como a de ouvir as crianças e acolher suas sugestões. Nesse sentido, destacamos alguns aspectos da análise das entrelinhas em que as crianças ofertaram aberturas para que as 
professoras, cada vez mais, compreendessem e se colocassem ao encontro dos aspectos culturais expressos pelas crianças. De um modo peculiar, as crianças buscavam aproximar as atividades propostas pelas professoras com seus contextos de experiências, de modo que a ação abordada em sala ou na quadra estabelecesse algum sentido e significado à sua vida cotidiana.

\footnotetext{
Numa aula de educação física, a professora pede ajuda para carregar os cones até o depósito da escola. Samuel, de pronto, se oferece para ajudar e começa a dizer que em sua casa também ajuda seu pai com as tarefas. "0 menino conta que ainda só pode ajudar a levar sacos de esterco para a horta de sua casa, mas que sua vontade mesmo é de poder guiar o caminhão de cana logo [...]" (Diário de campo XV, 20-10-2014).
}

No excerto verificamos que após lançar o pedido, a professora logo é atendida por Samuel, que aproveita a situação para socializar parte de sua rotina cotidiana. As falas corriqueiras das crianças necessitam da escuta atenta dos adultos, como forma de estarem abertos ao que o outro tem a dizer, reconhecendo o valor das ações do ponto de vista e da interpretação desse outro, seja em momentos de atividades escolares direcionadas, seja em momentos como o guardar dos materiais. Segundo Rinaldi (2012, p. 125), a escuta atua como premissa de qualquer relação de aprendizagem "- aprendizado que é determinado pelo 'sujeito aprendiz' e toma forma na mente desse sujeito por meio da ação e da reflexão." A escuta protagoniza meios para saber e aguçar falas acerca das experiências vividas em ambientes extraescolares, as quais enriquecem a prática cotidiana de ensinar e aprender.

Observou-se, então, que ambas as professoras se colocavam à disposição das crianças, em uma postura dialética e comprometida com o ofício. Entretanto, nas relações desencadeadas entre elas, raramente evidenciou-se uma discussão mais aprofundada do universo e das referências culturais das crianças de zona rural, gerando, dessa forma, alguns desencontros hierárquicos e culturais.

Por fim, reconhecemos que os espaços para as crianças expressarem os modos próprios de sentir, pensar e agir e suas formas de se relacionar com os outros não foram negligenciados, porém poderiam ser potencialmente mais aproveitados pelas docentes. 


\subsection{ASPECTOS EDUCATIUO-PEDAGÓGICOS NAS PRÁTICAS DOCENTES}

As práticas educativo-pedagógicas compreendem as ações docentes que transcendem apenas a preocupação em incutir conhecimentos escolarizantes nas crianças, ou seja, estão atreladas às ações do educar, para além da absorção passiva de conhecimentos ditos escolares. Tais práticas estiveram presentes nas ações das professoras. A título de exemplo, destacamos a prática de leitura de história feita pela pedagoga sobre a festa dos animais e que ocorria no céu:

\footnotetext{
[...] o personagem pássaro ficou gozando da tartaruga, pois esta não iria conseguir chegar ao céu, já que ela não poderia voar até lá. Neste momento a professora faz uma pausa e pergunta às crianças: "quais soluções podem ser dadas para que a tartaruga vá à festa?" Patrick começa a dizer em voz alta: "não tem o que fazer, se ela não avoa porque não tem asa, então ela não vai e vai ficar pra trás mesmo, profe". A professora intervém dizendo que na vida nem sempre temos as melhores possibilidades para conseguir com facilidade o que desejamos, mas que não podemos desistir antes de procurarmos soluções. Ouvindo o comentário feito pela professora, Henrique então sugere: "porque ela não chama outro animal grande que voa e sobe nele e vai junto?" (Diário de campo XV, 20-10-2014).
}

Ao aproveitar o contexto da história para refletir algumas situações da vida cotidiana, a prática pedagógica da professora transforma a sala de aula em um espaço oportuno para inter-relações de conhecimento e autoconhecimento, ancorados em meio às estratégias de ensino propostas pelo documento Ensino Fundamental de nove anos (BRASIL, 2004), os quais estão pautados na aprendizagem da leitura e escrita. A professora almejou que as crianças aprendessem os conteúdos formalizados, por exemplo, ao interpretar o texto e, ainda, superou tal objetivo ao buscar construir junto ao menino alguns valores da vida.

Em outra situação, ao terminar de passar os escritos na lousa, a pedagoga circulava entre as carteiras para ver quem estava concluindo a atividade, até deter-se aos afazeres de Felipe. 0 garoto vive na Fazenda Santa Helena, é pouco frequente nas aulas, e, por vezes, a professora pede a sua atenção/concentração nas atividades escolares e mais empenho nas tarefas de casa.

[...] parando ao lado de Felipe a professora questiona: "você está treinando escrever em casa? Porque, olha, a coisa tá feia, desse jeito vai chegar o final do ano e nada". Felipe apenas balança a cabeça com um gesto positivo. 0 menino demonstra-se ainda mais 'fechado'/encolhido na carteira e continua olhando fixamente para lousa, transferindo as letras para o caderno. Ela 
aproveita o contexto para dizer que não se pode trocar a letra $L$ pela $R$, sendo que palavrinhas como 'plástico' e 'folga' não podem ser escritas e nem faladas prástico e forga [...] (Diário de campo Vl, 17-09-2014).

A partir da análise do excerto, torna-se possivel compreender que a professora tentou não reduzir seus afazeres pedagógicos em situações puramente técnicas, ao demonstrar-se atenta e preocupada para com a aquisição da escrita pelo menino. Contudo, culmina em não considerar a existência da subjetividade e de necessidades próprias do menino, especialmente em relação ao modo coloquial da fala e de linguagens compatíveis aos saberes de origem das crianças. Nem se quer problematiza essas questões.

Continuando o processo investigativo, focalizamos a análise de uma inserção que contribuiu de forma ímpar para a compreensão e discussão de como ocorre o tratamento das atividades escolares focadas no contexto rural. 0 seguinte fragmento de diário de campo descreve o contexto da atividade:

A professora anuncia que irá retomar a leitura do livro de ontem. A obra intitula-se "Sai da frente vaca brava" e conta a história de vida de uma menina chamada Naná de dez anos que morava na fazenda, numa casa bem pobrezinha e afastada da cidade [...] A personagem tinha que ir a pé para a escola. Num dado momento, a professora interrompe a leitura, dizendo: "não era como vocês que tem o ônibus, ela ia andando, sozinha. $E$ vocês tem ônibus que passa quase que na frente de casa e tem um monte de gente que vive faltando." As crianças ouvem o comentário feito pela professora em silêncio. Retoma a história e conta que Naná acaba chegando muito cansada por tanto andar e, por isso, não consegue se concentrar nas liç̃es. Um belo dia, no caminho à escola, Naná encontrou uma vaca muito brava e, por isso, teve que desviar o caminho e chegou depois do recreio na escola. Novamente, a professora interrompe partes da história e questiona as crianças sobre o que estão achando e as incentiva a dizerem como pensam que será o final. Kauan, Letícia e Julieta são os mais participativos e vão tecendo outros contextos à história, colaborando com a professora na construção da aprendizagem [...] A história vai tomando rumo final. A vaca encontrada no caminho acaba virando amiga de Naná e a história abarca conceitos sobre a escassez de recursos para as pessoas que moram afastadas da cidade e sobre a exploração de mão de obra infantil [...] (Diário de campo XXVI, 21-11-2014).

0 principal objetivo do trabalho da pedagoga foi ofertar uma condição singular para que as crianças pudessem se reconhecer como parte de uma determinada cultura e construir identidades afirmativas à medida que se reconhecem, em partes, no conteúdo abordado na história. Assim, ao final da leitura ela faz uma relação entre a história e o contexto de vida dos estudantes de zona rural, dizendo: "tem muito a ver com vocês, pois 
também acordam cedo para esperar o ônibus passar, encontram obstáculos para chegar na escola e às vezes ainda atrasam ou faltam no dia [...]" (Diário de campo XXVI, 21-11-2014).

A breve discussão desencadeada entre as crianças e a professora possibilitou deter maior compreensão sobre a realidade rural, refletindo sobre ela. Segmentos do mesmo Diário revelam a interpretação das crianças: "gostei do livro porque a vaca ficava na escola junto com as crianças e eram amigas e também que o prefeito só faz as coisas boas quando vai um monte de gente lá falar e reclamar" (Letícia, 8 anos); "gostei de que as crianças vão todas juntas lá pra fazenda da Naná e lá brincam de tudo que nem a gente aqui." (Maria Luiza, 9 anos) (Diário de campo XXVI, 21-11-2014).

Sabemos que o cuidado da pedagoga em contemplar uma história sobre parte do universo rural reflete ao seu compromisso em tentar fazer da escola um espaço acolhedor e com perspectivas multiculturais. Em diálogo com Leite (2002), percebe-se a importância em respeitar e compreender as diferenças como marca da condição humana, iluminando o papel cultural da escola e defendendo o encontro de culturas, como forma de combate à hierarquização entre elas ou à subordinação de uma a outra.

Ainda que as crianças tenham conseguido estabelecer correlação com essa história, as Diretrizes Operacionais para a Educação Básica de escolas que atendem à demanda no campo (BRASIL, 2002) salientam que o reconhecimento do modo próprio de vida social, da diversidade e da identidade da população rural não pode ser feito de modo fragmentado e descontextualizado das verdadeiras condições de vida do público com o qual atua. Em outras palavras, apontamos que o diálogo sobre o contexto de vacas e exploração de mão de obra infantil não pertence à realidade de vida das crianças dessa escola, já que estas são filhos de trabalhadores assalariados na lavoura de cana-de-açúcar e possuem moradia na região rural concedida pelos patrões, para que o trabalhador (figura paterna) esteja integralmente próximo ao ambiente de trabalho.

Ao empreender atividades que pouco se aproximam do contexto de vida das crianças, estar-se-á colaborando ainda mais com mitos e estigmas de que a vida no campo é vivida de uma única forma, universalizante e uniformalizante. Nesse ínterim, a compreensão do universo cultural e especificidades dos sujeitos que compõem a escola são imprescindíveis para que a ação pedagógica seja pertinente. Ainda, cabe ressaltar que o projeto políticopedagógico dessa escola demonstra-se atento e articulado à realidade do seu alunado, de modo que a comunidade escolar venha a conhecer melhor e a valorizar a cultura local. Entretanto, em meio às práticas pedagógicas, por vezes, surgiram alguns equívocos no processo de desenvolvimento.

No decorrer do trabalho de campo, paulatinamente, evidenciamos o emprego de práticas educativo-pedagógicas em um exercício comprometido das docentes na constituição 
de conhecimentos escolares e da apreensão de valores inerentes à formação humana. Nesse processo, foi observada a atuação das crianças como agentes detentores das unidades de ensino, bem como de formação de valores e condutas socialmente desejáveis na cultura escolar urbana.

\section{CONSIDERAÇÕES FINAIS}

A partir da análise do trato pedagógico das professoras, concluímos que houve uma ação didática diretamente empregada com as crianças, com a intenção de formá-las para a vida em sociedade. Nesse sentido, Sommerhalder e Alves (2012, p. 241) aclaram que o processo empregado pelas docentes "[...] implica incorporar valores, comportamentos, conceitos, enfim, saberes que possibilitam à criança constituir-se como sujeito no interior de um determinado contexto sociocultural."

Este estudo evidenciou que ao mesmo tempo em que houve uma estruturação das práticas pedagógicas com foco na constituição de conteúdos escolarizantes voltados à formação integral do ser humano, pouco se verificou a oportunidade para as crianças expressarem/aprofundarem saberes oriundos de seus pertencimentos culturais. As relações entre alunado e professoras no ambiente escolar permitiu que as crianças coordenassem suas vontades e desejos com expectativas próprias, ao passo que as aç̃̃es docentes raramente utilizaram tais manifestações para esmiuçar valores e práticas emergidas no contexto de vida das crianças de zona rural.

Se no campo discursivo da educação a escola é compreendida como um espaço de apropriação e constituição de conhecimentos e habilidades que ultrapassam o âmbito da linguagem, da leitura e escrita, das lógicas matemáticas, de desenvolvimento de aspectos fisicos e motores, visando reconhecer as crianças como sujeito, valorizando os espaços fisicos e sociais nos quais elas estão inseridas, bem como proporcionando aprendizagens sociais, culturais e de valores (BRASIL, 2004), consideramos necessário ampliar a discussão sobre os processos de formação inicial do professor que possivelmente encontrará crianças de zona rural em seu ambiente de trabalho e, do mesmo modo, a formação continuada para os que já atuam com esse público.

Tal discussão é fundamental, pois, para além de sugerir à formação docente um processo dinâmico, cíclico e inacabado, oferta ao exercício docente especificidades da demanda no campo, no que concerne às raízes históricas e políticas dessa população. Como grande mérito, trazem-se as crianças e suas culturas para o centro das práticas 
pedagógicas nas distintas etapas da educação básica, desse modo, não se restringindo ao contexto de vidas e saberes majoritariamente urbano.

Por fim, compreendemos a escola como um espaço que busca constituir, junto com os sujeitos que a ele pertencem, bases para muitas aprendizagens necessárias aos entendimentos, reflexões e enfrentamentos de situações cotidianas. Para tanto, defendemos a construção de práticas pedagógicas que reconheçam e valorizem as culturas de pares, possibilitando um lugar de encontro de saberes.

\section{REFERÊNCIAS}

ANDRÉ, M. E. D. de. Etnografia da prática escolar. Campinas: Papirus, 1994.

ARROYO, M. G. A. Escola, cidadania e participação no campo. Em Aberto, Brasília, ano 1, n. 9, p. 1-7, 1982. Disponivel em: http://emaberto.inep.gov.br/index.php/emaberto/article/view/1400/1374. Acesso em: 01 out. 2018.

BARDIN, L. Análise de Conteúdo. Lisboa: Edições 70, 2009.

BEZERRA NETO, L. Educação do campo ou educação no campo? Revista Histedbr On-line, Campinas, n. 38, p. 150-168, 2010. Disponivel em: https://periodicos.sbu.unicamp.br/ojs/index.php/histedbr/article/ view/8639696. Acesso em: 21 ago. 2018.

BIAZZO, P. P. Campo e rural, cidade e urbano: distinções necessárias para uma perspectiva crítica em geografia agrária. In: ENCONTRO NACIONAL DE GRUPOS DE PESQUISA, 4., 2008, São Paulo. Anais [...] São Paulo: ENGRUP, 2008. p. 132-150.

BOGDAN, R. C.; BIKLEN, S. K. Investigação qualitativa em educação. Porto: Porto Editora, 1994.

BOSI, A. Cultura brasileira e culturas brasileiras. In: BOSI, A. Dialética da Colonização. São Paulo: Companhia das letras, 1992. p. 308-345.

BRASIL. Ministério da Educação e do Desporto. Ensino Fundamental de nove anos: orientações gerais. Brasilia, DF, 2004.

BRASIL. Conselho Nacional de Educação. Câmara de Educação Básica. Diretrizes Operacionais para a Educação Básica nas Escolas do Campo. Brasília, DF: [s. n.], 2002.

BRASIL. Ministério da Educação. Secretaria de Educação Básica. Diretoria de Currículos e Educação Integral. Diretrizes Curriculares Nacionais Gerais para a Educação Básica. Brasília, DF: [s. n.], 2003.

CORSARO, W. A. Sociologia da infância. Porto Alegre: Artmed, 2011. 
DAMASCENO, M. N.; BESERRA, B. Estudos sobre educação rural no Brasil: estado da arte e perspectivas. Educação e Pesquisa, São Paulo, v. 30, n. 1, p. 73-89, 2004. Disponível em: http://www.revistas. usp.br/ep/article/view/27925/29697. Acesso em: 01 out. 2018.

FIORI, E. M. Educação libertadora. In: FIORI, E. M. Textos escolhidos, v. ll, Educação e Polltica. Porto Alegre: L\&PM, 1991. p. 83-95.

FREIRE, P. Pedagogia da autonomia: saberes necessários a prática educativa. São Paulo: Paz e Terra, 1996.

FREIRE, P. Professora sim tia não: cartas a quem ousa ensinar. São Paulo: Olha d'Água, 1993.

IBGE. 2010. Disponível em: http://www.ibge.gov.br/home/estatística/população/cendo2000/universo. Acesso em: 20 jun. 2014.

INSTITUTO NACIONAL DE ESTUDOS E PESQUISAS EDUCACIONAIS ANISIO TEIXEIRA. Panorama de educação no campo. Brasília, DF: MEC, 2010.

LEITE, M. I. F. P. Repensando a escola - com a palavra: a crianças da área rural. Pró-Posições, Campinas, v. 13, n. 1 (37), p. 176-185, 2002. Disponivel em: https://periodicos.sbu.unicamp.br/ojs/index.php/ proposic/article/view/8643977. Acesso em: 01 out. 2018.

LUDKE, M; ANDRÉ, M. E. D. A. Pesquisa em educação: abordagens qualitativas. São Paulo: E.P.U., 2012.

MARTINS, J. S. de. As coisas no lugar. In: MARTINS, J. S. de. Introdução Crítica à Sociologia Rural. São Paulo: Hucitec, 1981. p. 9-42.

OLIVEIRA, M. W de. Pesquisa e trabalho profissional como espaços e processos de humanização e de comunhão criadora. Caderno Cedes (Impresso), Campinas, v. 29, n. 79, p. 309-321, jan./abr. 2009.

RINALDI, C. Diálogos com Reggio Emilia: escutar, investigar e aprender. Tradução: Vania Cury. São Paulo: Paz e Terra, 2012.

SANTOS, M. Metamorfose do espaço habitado. São Paulo: Hucitec, 1988.

SILVA, P. B. G. Aprender a conduzir a própria vida: dimensões do educar-se entre afrodescendentes e africanos. In: BARBORA, L. M. de A; SILVA, P. G. e S; SILVÉRIO, V. R. (org.). De preto a afro-descendente: trajetos de pesquisa sobre relações ético-raciais no Brasil. São Carlos: EDUFSCar, 2003. p. 181-197.

SOMMERHALDER, A.; ALVES, F. D. Infância e Educação Infantil: aspectos inconscientes das relações educativas. Paidéia, Ribeirão Preto, v. 22, n. 52, 241-249, 2012. Disponível em: http://www.scielo.br/pdf/ paideia/v22n52/10.pdf. Acesso em: 27 mar. 2018. 
STROPASOLAS, V. L. Os significados do corpo nos processos de socialização de crianças e jovens do campo. In: ARROYO, M. G.; SLVA, M. R. da. (org.). Corpo Infância: exercícios tensos de ser criança. Petrópolis, RJ: Vozes, 2012. p. 153-184.

VEIGA, J. E. A atualidade na contradição urbano x rural. 2004. Disponivel em: http://www.econ.fea.usp. br/zeeli/. Acesso em: 21 jun. 2018.

Endereços para correspondência: Centro de Pesquisa da Criança e de Formação de Educadores da Infância (Cfei), Departamento de Educação Fisica e Motricidade Humana, Universidade Federal de São Carlos, Rodovia Washington Luis, km 235, 13565-905, São Carlos, São Paulo, Brasil; luanazanotto@ yahoo.com.br 